\title{
\begin{tabular}{l|l|l|l}
$\mathbf{C}$ & $\mathbf{O}$ & $\mathbf{P}$ & $\mathbf{E}$
\end{tabular} \\ Member since 2018 JM13710
}

EUROPEAN SPATIAL RESEARCH AND POLICY

Volume 27

Number 1

http://dx.doi.org/10.18778/1231-1952.27.1.04

\author{
Veronique SCHUTJENS* (D), Maarten KRUGER ${ }^{* *}$
}

\section{THE ROLE OF PROXIMITY IN RESOURCES EXCHANGED BY INCUBATEES OF BIOPARTNER CENTER LEIDEN, THE NETHERLANDS}

\begin{abstract}
Subject literature assumes that spatial proximity stimulates collaboration in thematic clusters. However, even in micro-scale settings, resource exchange is rare or entails only tangible resources. We empirically unravel how specific proximity indicators relate to the types of resources exchanged in incubatees' business relationships. Based on 118 business relationships of incubatees, we conclude that on the micro-scale of an incubator, site proximity to another incubatee has a limited relation and geographical proximity to business partners outside the incubator has no relation to the types of resources exchanged. For the latter business relationships, personal similarity positively relates to the exchange of specific business knowledge resources.
\end{abstract}

Key words: types of resources exchanged, business relationships, spatial proximity, personal similarity, university business incubator.

\section{INTRODUCTION}

"No mating without meeting" is a well-known phrase in the sociological literature on social capital (Verbrugge, 1977, p. 577). Additionally, in studies on entrepreneurship, economic geography and spatial economics, it is understood that faceto-face interaction between firms is necessary to enable the exchange of resources, which may build trust and ultimately result in stable networks where collaboration and innovation take place. As such, it has been assumed that as a result of spatial proximity among firms, a thematic geographical cluster stimulates collabo-

\footnotetext{
*Veronique SCHUTJENS, Utrecht University, Faculty of Geosciences, Princetonlaan 8A, 3584 CB Utrecht, the Netherlands, e-mail: v.a.j.m.schutjens@uu.nl, ORCID: https://orcid.org/0000-0002$8530-4542$

** Maarten KRUGER, Bureau Buiten, Achter Sint Pieter 160, 3512 HT Utrecht, the Netherlands, e-mail: maarten.kruger@bureaubuiten.nl, ORCID: https://orcid.org/0000-0002-9904-5182
} 
ration and innovation (McCann and Folta, 2011; Katz et al., 2015). However, there is evidence that even in micro-scale settings specifically developed to foster inter-firm networks, such as university business incubators (UBIs), professional relationships between firms do not develop automatically or easily (Cooper et al., 2012; Fuzi, 2015; Parrino, 2015). Furthermore, it seems that even when business relationships do develop, firms rarely exchange valuable resources with various parties (Soetanto and Jack, 2011) and seldom formalise their collaborations (McAdam and Marlow, 2008).

It remains unclear why many business networks among incubatees, located at close physical proximity in an incubator, are small (Parrino, 2015) and, in particular, why resource exchange is rare. To form inter-firm linkages and actually exchange resources, firms must be aware of other incubatees' presence and activities, must be in need of the resources they might exchange (Redondo-Carreto and Camarero-Izquiedo, 2017), and must have easy access to other firms. At the micro-level of an incubator, firms are spatially proximate to each other but still might find it difficult to actually access and contact other firms. This might be due to physical barriers, such as multiple incubator buildings, locked doors between buildings, or even limited access to other floors within buildings. Therefore, spatial proximity might reduce barriers such as travel time (see Boschma, 2005; Torre and Rallet, 2005), but the actual face-to-face contacts that facilitate the exchange of resources in specific business locations require ease of access and, therefore, proximity at a more detailed, micro-level (Redondo-Carreto and Camarero-Izquiedo, 2017). Furthermore, as the phrase "no mating without meeting" suggests, a match between partners is necessary for interaction and resource exchange. Firms, individuals and entrepreneurs who share characteristics might be more prone to interact and form relationships than dissimilar ones. Here, another saying applies: "birds of a feather flock together". That is, likeminded and similar people tend to connect, which might facilitate resource sharing or resource exchange.

However, the effects of both spatial proximity at the micro-level and similarity between business partners on the actual resources exchanged might differ between specific types of resources. We explicitly exclude trade in the value chain (supply and demand linkages) and focus on resources that are necessary to produce and sell products, the so-called 'business-relevant' resources. The trade and sharing of tangible assets, such as equipment, materials, and office space, is facilitated by close physical proximity between business partners. However, frequent and intensive face-to-face contact and personal similarity might be even more crucial for intangible knowledge exchange on both generic and more specific business matters, such as market information and product development, respectively. This distinction between tangible and intangible resources relates to the difference between explicit and tacit knowledge, as proposed by Polanyi (1958). The exchange of tangible resources involves the sharing or trading of physical objects 
such as products, equipment, machinery, space, or instruments (Van Rijnsoever et al., 2017). In contrast, intangible resources refer to business knowledge, which might be explicit or coded when it can be easily documented and exchanged, such as generic information, or it can be tacit when it is personal, firm-specific and context-bound knowledge (see Usman et al., 2019; Mason et al., 2012). For new firms and incubatees who are often in the early phases of a firm's life cycle or for small firms, new knowledge and information is crucial for business survival and growth, but, at the same time, protecting their specific competitive advantage is also important (McAdam and McAdam, 2006; Massaro et al., 2019). Due to the need to cope with these conflicting business interests, incubatees may differentiate between sharing generic business information (about markets or suppliers or general ideas) and sharing more valuable, specific business knowledge (for instance, on close collaboration or research and development). It is this distinction between resource types, i.e. tangible resources and intangible (both generic and specific business knowledge) resources, that is the key of this paper. Instead of focusing on proximity factors driving network creation and the maintenance of business relationships (the 'ties' or 'tubes' themselves), this article emphasises the role of proximity in the types of resources that actually 'flow' through these relationships between business partners.

This study investigates whether and how specific dimensions of proximity to business partners relate to the exchange of tangible and intangible resources by incubatees of the UBI BioPartner Center Leiden, the Netherlands. These business partners may be located within or outside the incubator.

Remarkably little is known about the variation in incubatees' resources exchanged and thus their actual use of business networks (Cooper et al., 2012; Soetanto and Jack, 2011; McAdam and Marlow, 2008). In focusing on actual resources exchanged in incubatees' business relationships, we contribute to the existing knowledge in several ways. First, we hope to contribute to the old but ongoing academic debate concerning the role of proximity in business networks at the micro-level. Further, according to Boschma (2005), the geographical proximity of businesses is not an absolute prerequisite but a catalyst of collaboration, especially when other types of proximity are absent. Second, as we apply his ideas to the value of spatial proximity to resource exchange in business relationships at the micro-level of an incubator setting, we also add to the literature on incubator configurations (see Hackett and Dilts, 2004). This literature entails the drivers of the mere existence of inter-firm relationships (McAdam et al., 2006; Cooper et al., 2012) and of knowledge exchange and interactions in specific coworking spaces (Parrino, 2015; Fuzi, 2015), incubators (Redondo-Carretero and Camarero-Izquierdo, 2017) or a specific company division (Usman et al., 2019). However, whereas the latter scholars qualitatively investigated business relationships, this paper adapts quantitative methods to investigate whether spatial proximity and similarity between two business partners relate to the types of resources ex- 
changed in business relationships. We apply the name-generator technique used in social network analyses to detect business partners and their attributes. As such, this is an explanatory study using quantitative methods to assess whether proximity dimensions relate to the resource types exchanged. A third contribution is our emphasis on personal contacts, as Redondo-Carreto and Camarero-Izquiedo (2017) have recently advocated. By introducing an indicator of personal similarity in the analysis of the resources exchanged in incubatees' relationships, this paper answers the call for empirical research and the operationalisation of concepts related to proximity (Caniëls et al., 2014) and the mechanisms related to personal relationships - instead of only cost and efficiency drivers related to bridging physical distance (Redondo-Carreto and Camarero-Izquiedo, 2019).

In the empirical part of the paper, we use an actor-centred approach by focusing on the types of resources exchanged in the business relationships of the incubatees of BioPartner Center Leiden. Using the name-generating technique in semi-structured interviews with 17 incubatees, combined with a questionnaire, we traced the resources exchanged in 118 unique relationships between business partners inside or outside the incubator, from which proximity indicators could be calculated. The resulting data set enabled a quantitative investigation of the relationship between three specific indicators of business partners' proximity on the one hand and the types of resources actually exchanged on the other. As the spatial proximity of businesses at the micro-level within an incubator has a quite different meaning than in relationships with businesses outside the incubator, we differentiated between business relationships in the two settings (inside and outside the incubator).

After a short literature overview on the dimensions of proximity that relate to resource exchange in business relationships, section 3 describes the context and spatial configuration of BioPartner Center Leiden. Section 4 explains the data and methods used to capture the dimensions of proximity, similarity, and resource exchange. In section 5, we present the results of the role of proximity in the resources exchanged in the business relationships of UBI Leiden incubatees. Finally, section 6 concludes the article.

\section{LITERATURE}

\subsection{Dimensions of proximity}

Thus far, both business relationships and university business incubators have received ample academic attention. Regarding the former, many studies show a positive link between entrepreneurial networks and business survival and growth. Business relationships are an important means of gaining access to re- 
sources, especially for firms in vulnerable strategic positions such as start-ups (Eisenhardt and Schoonhoven, 1996; Soetanto and Jack, 2011) or for entrepreneurs with small or biased personal networks (see Mozumdar et al., 2019). Regarding (university) business incubators, many studies have focused on their impact on the performance of start-ups, either via direct support (funding, office space) or via indirect support by giving start-ups access to other businesses or organisations (Buys and Mbewana, 2007; Cooper et al., 2012; Peters et al., 2004; McAdam and Marlow, 2008; Ahmad, 2014; Van Rijnsoever et al., 2017; Eveleens et al., 2017).

Scholars have long elaborated on the concept of 'proximity' as a facilitator of contacts, networks and resource exchange (for an extensive overview, see Caniëls et al., 2014). For instance, in sociology, the proximity concept gave way to approaches emphasising actor similarity (McPherson et al., 2001). In economics, Williamson's transaction cost theory (1958) is the main pillar of the argument that firms and entrepreneurs seek out repeated and standardised business relationships to reduce the costs of new contracts. In their search for and efforts to maintain stable and routinised business contacts to reduce uncertainty and thus avoid costs, entrepreneurs of particularly new or young firms tend to favour close-by firms. According to Harrison in his critical conceptualisation of industrial clusters, repeated interaction is facilitated by personal contact, which in turn benefits from geographical proximity: "proximity leads to experience leads to trust" (Harrison, 2007, p. S116). At the crossroads of sociology and economics, the work of Granovetter (1985) on embeddedness created novel insights into the role of social contacts in economic transactions, paving the way for the acknowledgement of the importance of experience, trust and reciprocity between economic actors and the importance of the distance between them. Based on the notion that knowledge spillovers are place-bound (Jaffe et al., 1993), economic geographers interested in intensive (innovation) business relations have focused on distance as measured by geographical proximity. In accordance with the work of the French School of Proximity Dynamics, academics have developed different dimensions of proximity (D'Este et al., 2012; Beugelsdijk and Mudambi, 2013). In his seminal article on proximity and innovation, Boschma (2005) argued that in addition to the traditional geographical interpretation of physical distance, proximity consists of several components, each of which distinctively impacts knowledge exchange, learning, and innovation. Cognitive proximity refers to actors sharing the same reference and knowledge space, and is a prerequisite for successful knowledge sharing. Organisational proximity refers to the closeness of actors in organisational terms and can stimulate two organisations to collaborate. Institutional proximity refers to whether two parties share an institutional environment. Social proximity consists of "embedded, trust-based interaction between actors" (Boschma, 2005, p. 64), and geographical proximity refers to the spatial distance between two parties. In response to Boschma's plea for more empirical research to isolate the effects of 
these different dimensions of proximity, Parrino (2015) studied spatial aspects of knowledge flows in two contrasting coworker spaces and concluded that collaborations and relationships are rarely created in the absence of an organisational structure supporting other forms of proximity. In other words, co-location itself seems insufficient for interaction between co-workers. This notion is linked to the so-called paradox of proximity: being too close to one another might dampen the benefits of interaction (Micek, 2019).

As most incubatees in a small-scale mono-sectoral setting, as in BioPartner Centre Leiden, can be expected to be cognitively, organisationally, and institutionally proximate to one another (see Cooper et al., 2012), these forms of proximity are of limited usefulness in explaining variation in the resources exchanged. Spatial distance between incubator firms, of course, is also extremely small. However, as 'running into each other' and engaging in face-to-face interactions are important for building networks, experiences and, finally, trust, within incubators, the physical distance between firms may still matter for the formation of business relations and especially the types of resources exchanged. Spatial proximity can, therefore, be conceptually divided into two components.

Regarding incubator-external relationships, geographical proximity can be applied in its original meaning as the spatial distance between two parties. In general, geographical proximity fosters collaboration between parties because the time and the effort required to meet or to visit the other party decreases as spatial proximity increases. However, it should be noted that geographical proximity is "neither a necessary nor a sufficient condition" for inter-firm learning and collaboration (Boschma, 2005, p. 620) but should instead be regarded as an additional catalyst of collaboration between parties that were already likely to collaborate (Boschma, 2005; D'Este et al., 2012). For incubator-internal relationships, however, this study adopts a more small-scale geographical notion: "within-incubator site proximity" (or just "site proximity"), referring to the relative physical distance between two incubatees, such as whether they are located in the same incubator building or on the same floor. Site proximity between two firms at the micro-scale of an incubator seems to facilitate collaboration as well, without being necessary or sufficient per se (Parrino, 2015). Proximity, then, simply increases the frequency of contacts and, as such, helps incubatees build and maintain networks. In 1987, Sweeney found that "the probability of two persons communicating at least once a week drops from 0.98 at a separation distance of 2 meters to 0.06 at 50 meters. Distance between organizations has the same effect" (in McAdam et al., 2006, p. 463). Accordingly, site proximity matters because it makes an encounter between two parties more likely. In their study on an incubator in the USA, Cooper et al. (2012) also found empirical evidence of a positive effect of site proximity on the likelihood of collaboration between two firms in the same incubator. In that ethnographic study, several entrepreneurs stated that they collaborated more often with incubatees located on the same floor than with incubatees located on other floors. 
In addition to site proximity and geographical proximity, both referring to physical or spatial distance, the influence of a third factor on resource exchange is analysed. This factor is related to the social proximity dimension to which Boschma (2015) referred. Because co-working spaces, including small-scale incubators, can be regarded as "microclusters" (Capdevila, 2015, p. 20), the individual rather than the firm is the focal actor. By emphasising the role of individual entrepreneurs in creating and maintaining business contacts at this micro-scale of a university incubator, this study combines the notions of personal proximity (Caniëls et al., 2014) and social similarity (Vissa, 2010). Caniëls et al. proposed the notion of personal proximity, referring to the proximity between individuals in terms of "personal characteristics and behaviors, which may be an important factor to determine the 'click' between two individuals" (p. 6). As such, personal proximity is the result of individuals having similar characteristics as well as similar personality traits. The "click" that occurs as a result of being similar, best described as a sense of mutual understanding and respect, is a key aspect of personal proximity and benefits interaction and collaboration in at least three ways. First, due to personal proximity and the resulting click, actors can communicate more easily because they share common knowledge, meanings, vocabulary, attitudes, and beliefs (Caniëls et al., 2014; Vissa, 2010). Second, a high degree of personal proximity enables individuals to predict the behaviour of their network partners, which fosters trust and facilitates the exchange of specialised or tacit knowledge, i.e., intangible resources. Third, individuals who are personally proximate to each other generally perceive their interactions as more pleasant and rewarding.

The concept of personal proximity strongly relates to the notion of social similarity (Vissa, 2010). According to Vissa, social similarity refers to the degree of similarity in characteristics such as ethnicity, gender, and age. Vissa (2010) stated that if two individuals are alike in a number of characteristics, they feel that they pertain to the same group. Individuals are more likely to perceive out-group members (who are not similar to them in terms of these attributes) as more dishonest, untrustworthy and uncooperative than in-group members (Vissa, 2010).

However, the concept of social similarity differs from the personal proximity concept in two important ways. First, Vissa's notion of social similarity only refers to similarity as such and does not refer to the resulting personal clicking of personal proximity. In that sense, proximity goes one step further than similarity because proximity is related to the quality and nature of the relationship, whereas similarity is the mere combination of characteristics of two individuals. Second, for Vissa's social similarity, the social context is important because it is the feeling of belonging to the same social group, and that stimulates trust and collaboration. In contrast, personal proximity is relevant in a personal context because it is the shared characteristics plus the personal click between two individuals, rather than the feeling of belonging to a larger social group, which fosters trust and collaboration. 
In combining social similarity and personal proximity concepts, this paper focuses on personal similarity. On the one hand, personal similarity emphasises the personal rather than the social aspect because it only looks at whether the personal characteristics of two individuals are similar, regardless of the larger social context or a feeling of belonging to a group. On the other hand, personal similarity adopts the aspect of similarity, rather than proximity, because it only looks at whether individuals are similar, not at whether this results in the feelings of proximity. Thus, personal similarity refers to whether two individuals are similar in terms of a number of personal characteristics, such as age, gender, ethnicity and educational level.

\subsection{How do dimensions of proximity matter for the resources exchanged by incubatees?}

Site proximity has been recognised as a factor that stimulates the exchange of resources between parties located in the same business incubator. However, little is known about whether site proximity relates to which resources are exchanged in a business relationship. Nevertheless, based on the findings of Cooper et al. (2012), we expect site proximity to mainly stimulate the exchange of tangible resources and generic business knowledge, as well as specific business knowledge, but the latter to a more limited extent. Cooper et al. analysed the communication network among a number of incubatees located in a UBI, finding that most interactions are face-to-face and mostly occur in hallways, in elevators, and at coffee machines. Similarly, McAdam and Marlow (2008) found that networking activities mainly took place in office corridors. In such interactions, the main resource exchanged appeared to be business-related information (Cooper et al., 2012). Consistent with the findings of Cooper et al. and McAdam and Marlow, we also expect that a faceto-face interaction in which generic business information is exchanged is more likely to arise if two parties are located on the same floor or in the same building. Additionally, for practical reasons, we expect that the exchange of tangible resources, particularly laboratory equipment and facilities, is more likely to occur if two parties are located in each other's vicinity. Sharing a laboratory with a neighbour is easier than sharing a laboratory located 200 metres away from your office. Moreover, we expect that the effect of site proximity on the exchange of specific business knowledge is not as strong as its effect on the exchange of generic knowledge and tangible resources. In other words, we expect that research collaborations and joint product development are not necessarily more likely to arise between two parties located on the same floor or in the same building. As we presume that specific business knowledge is more valuable to a firm's success and performance - and therefore its strategy - than generic business information and tangible resources, we expect that incubatees will look more actively for partners with whom 
to exchange specific business knowledge. Thus, regarding these highly valuable and specific knowledge exchanges, incubatees will be less hindered by the fact that a business partner is located on a different floor or in a different building.

Regarding geographical proximity, more is known about its effect on the types of resources exchanged in incubator-external relationships. In 2004, Smith and Powell showed that especially in biotechnology, specialist knowledge acquired from external network partners spurs innovation. However, another question arises here: does distance matter? Both Agrawal et al. (2008) and Boschma (2005) provided reasons to believe that if two parties are geographically proximate, they are more likely to exchange specific human capital resources. In his conceptual account, Boschma (2005) asserted that geographical proximity plays a role in interactive learning and innovation, although the role of geographical proximity should always be assessed in relation to other types of proximity. According to Agrawal et al. (2008), geographical proximity between two parties increases the probability of knowledge flows. A possible reason for this, although not mentioned by Agrawal et al. or Boschma, is that geographical proximity can foster interactions and, in the end, mutual trust, which is especially important if two parties are bound to work on the same project together for a long time, as is the case in the exchange of specific human capital knowledge. In more practical terms, this means that if two parties are located close to each other, they are more likely to work on a research project together or to develop a product together than to exchange any other resource type (such as financial resources or business information).

In addition, the role of personal similarity in the types of resources that two parties exchange seems to be equal for incubator-internal and incubator-external relationships. As personal similarity seems important for building trust, it is likely that parties sharing the same characteristics exchange those types of resources that require a high degree of trust. Again, trust seems to play a large role in the exchange of specific human capital resources, i.e. when two parties work together on a research project or on developing a new product. Such long-term collaborations involve a large degree of knowledge exchange, which, according to Caniëls et al. (2014), is facilitated by personal proximity. Moreover, in the exchange of specific human capital resources (i.e. specific knowledge), smooth communication is essential. Since Caniëls et al. argued that personal proximity facilitates communication between actors, it can be expected that personal similarity is positively related to the exchange of specific human capital resources.

\subsection{Other drivers of resource exchange between businesses}

There is ample reason to believe that the characteristics of both a firm and an entrepreneur affect the types of resources that a firm exchanges with other parties. Regarding firm characteristics, the age of a firm can have a positive effect on the 
share of tangible resources that the firm exchanges. Already in 1988, Bygrave asserted that investing in biotechnology start-ups comes with high risk. Especially in the start-up phase, when the product exists only in the entrepreneur's head, venture capitalists face a high degree of uncertainty related to such factors as the talent of the entrepreneur, market demand, and the further development of the product. Similarly, Behrens et al. (2012) argued that investing in a young company is riskier for capital investors than investing in an older company. Younger companies are not as attractive to capital investors as older companies: younger companies are more prone to failure, have not yet established a good reputation, and have not yet demonstrated the ability to bring their product to the market (Behrens et al., 2012). However, young companies may be prone to failure not because they are young but because they are small. This hypothesis has been dubbed the "liability of smallness" (Freeman et al., 1983, p. 692). Accordingly, it may be the case that capital investors are more hesitant to invest in smaller companies than in larger companies. Thus, the size of a firm may be negatively related to the share of financial (and therefore tangible) resources that a firm exchanges.

Concerning entrepreneurial characteristics, it appears that female entrepreneurs, young entrepreneurs, and inexperienced entrepreneurs all have limited access to business contacts in comparison to male, old and experienced entrepreneurs. This limited access negatively affects the share of tangible resources exchanged in the business network in particular because financial resources (classified as tangible resources) are generally harder to obtain than other resource types (Czarnitzki and Hottenrott, 2011; Zeng et al., 2010). With regard to gender, Verheul and Thurik (2001) argued that female entrepreneurs have less access to financial resources than male entrepreneurs because men are more likely than women to have prior entrepreneurial experience. Moreover, women are more likely to work part-time than men and, therefore, have less time to maintain and expand their networks (Verheul and Thurik, 2001). Blisson and Rana (2001) also argued that women have less access to associations, networks and clubs, or, as they call it, to the "old boys' network". Additionally, the age of entrepreneurs active in an enterprise may influence the types of resources exchanged in the business network. According to Snel and Bruins (2004), start-ups founded by older entrepreneurs collaborate more often with other enterprises than do start-ups founded by younger entrepreneurs. This may be because older entrepreneurs have more (entrepreneurial) experience, which results in more access to contacts in their network. Finally, according to the argument of Verheul and Thurik, and Snel and Bruins, it is not the age of an entrepreneur per se but the underlying factor of prior entrepreneurial experience that influences the resources exchanged in a business network. For instance, Sørheim (2003) asserted that entrepreneurial experience can provide entrepreneurs with access to investors. Zhang (2011) confirmed that entrepreneurs who have established a firm in the past can acquire more venture capital than entrepreneurs with no prior entrepreneurial experience. 
Table 1 summarises the literature regarding the relationships among proximity, similarity and firm and entrepreneurial experience on the one hand and the resources exchanged in business relationships on the other.

Table 1. Literature findings on factors related to the types of resources exchanged in business relationships

\begin{tabular}{|c|c|c|c|c|}
\hline \multirow{3}{*}{ Dimension } & \multirow{3}{*}{ Variables } & \multicolumn{3}{|c|}{$\begin{array}{c}\text { Types of resources exchanged in } \\
\text { business relationships }\end{array}$} \\
\hline & & \multirow[b]{2}{*}{$\begin{array}{l}\text { Tangible } \\
\text { resources }\end{array}$} & \multicolumn{2}{|c|}{ Intangible resources } \\
\hline & & & $\begin{array}{c}\text { Generic } \\
\text { business } \\
\text { knowledge }\end{array}$ & $\begin{array}{c}\text { Specific } \\
\text { business } \\
\text { knowledge }\end{array}$ \\
\hline \multirow{3}{*}{$\begin{array}{l}\text { Proximity and similarity } \\
\text { dimensions }\end{array}$} & Personal similarity & - & - & + \\
\hline & Site proximity & + & + & - \\
\hline & Geographical proximity & - & - & + \\
\hline \multirow{2}{*}{ Firm characteristics } & Firm age & + & 0 & 0 \\
\hline & Firm size (\# of employees) & + & 0 & 0 \\
\hline \multirow{3}{*}{$\begin{array}{l}\text { Entrepreneurial } \\
\text { Characteristics }\end{array}$} & Entrepreneur age & + & 0 & 0 \\
\hline & Gender (male) & + & 0 & 0 \\
\hline & Entrepreneurial experience & + & 0 & 0 \\
\hline
\end{tabular}

Note: Explanation of signs: "+" stands for a positive effect and "-" a negative effect on resources exchanged. In cases of a 0 , no literature was found on the effect.

The relationships tested in this study are indicated by larger font, bold.

Source: own work.

The following two hypotheses are tested in the empirical section of this study:

Hypothesis 1: In business relationships where entrepreneurs are personally similar, the exchange of specific business knowledge is more likely than in relationships between businesses whose entrepreneurs are personally dissimilar. Especially in the exchange of specific knowledge, mutual trust and good communication are essential. According to Caniëls et al. (2014) and Vissa (2010), personal proximity fosters both, and it is expected that the more personally similar two parties are, the more likely they are to exchange specific human capital resources.

Hypothesis 2: In incubator-internal relationships between businesses whose firms'sites are spatially proximate, the exchange of tangible resources and generic knowledge is more likely than in business relationships characterised by a low degree of site proximity. Based on previous studies, site proximity seems to be 
particularly conducive to the exchange of tangible resources, such as equipment, and generic business knowledge, such as market information. Site proximity does not seem to have a similarly strong effect on the exchange of specific business knowledge.

\section{SETTING THE STAGE: BIOPARTNER CENTER LEIDEN}

The university incubator BioPartner Center Leiden was founded in 2007 as a merger of the Center for Academic Companies of Leiden Foundation ("Stichting Academische Bedrijven Centrum Leiden") and the Life Science Incubator Leiden Foundation ("Stichting Life Science Incubator Leiden"). The foundation was funded by the University of Leiden, the academic hospital of Leiden ("Leids Universitair Medisch Centrum") and the municipality of Leiden (BioPartnerCenter Leiden, n.d.) The university incubator "aims to enhance the growth and innovation potential of life science companies" (BioPartnerCenter Leiden, n.d.) To this end, the foundation offers accommodations and laboratory facilities to businesses operating mostly in the biotechnology sector and often specialise in pharmaceuticals and vaccinations. The incubator's focus is on entrepreneurs who have already invested considerable time and effort in setting up a company. At the time of the empirical research, i.e. in April 2013, according to incubator management, 47 companies and organisations were located in the incubator. Firms may stay in the incubator during two five-year stages: the incubator stage and the accelerator stage (Kruger, 2013).

BioPartner Center Leiden is located in the vicinity of a number of large biotechnology companies (Centocor, Crucell, Pharming, OctoPlus, TNO), the University of Leiden and the university hospital LUMC. At the time of the research, BioPartner Center Leiden housed firms in three different buildings (see the spatial layout in Fig. 1).

The first two buildings ("BioPartner BP1 and BP2") are identical, with approximately 15 metres space between the two entrances. At the time of the empirical research, BioPartner 1 housed 10 businesses and BioPartner BP 2 accommodated 11 businesses. The third building ("BioPartner BP3") is located opposite the first two, approximately 50 metres away. At the time of the data collection, this building housed 23 different businesses. Three firms were located in two or more different buildings.

A number of characteristics of BioPartner Center Leiden stimulated the formation of business networks within the incubator (or "incubator-internal contacts"). Most firms were active in the same sector, i.e. the red biotechnology sector, where organisms are used in medical and pharmaceutical research to improve human 
health, e.g. by developing vaccines. This specific industry focus makes collaboration more profitable for incubatees and, therefore, more probable. Moreover, all firms in the incubator were located in each other's vicinity, with a maximum distance of approximately 100 metres; the layout of the incubator and its open design were important factors that stimulated the formation of an incubator-internal network. The incubatees could look through their windows and see other offices, and they shared a kitchen on each floor of each building, which increased the likelihood of incidental encounters. As mentioned by the incubator manager, BioPartner Center Leiden regularly hosted networking events meant to stimulate the formation of networks. BioPartner Center Leiden had free facilities where incubatees, external parties, and the university could organise lectures or networking events/drinks. Whereas in 2013, incubator management did not actively organise such events itself, it did support others who organised them. Finally, the incubator manager actively linked the incubatees to external parties (one-to-one support) whenever a company expressed a need for help in building networks.

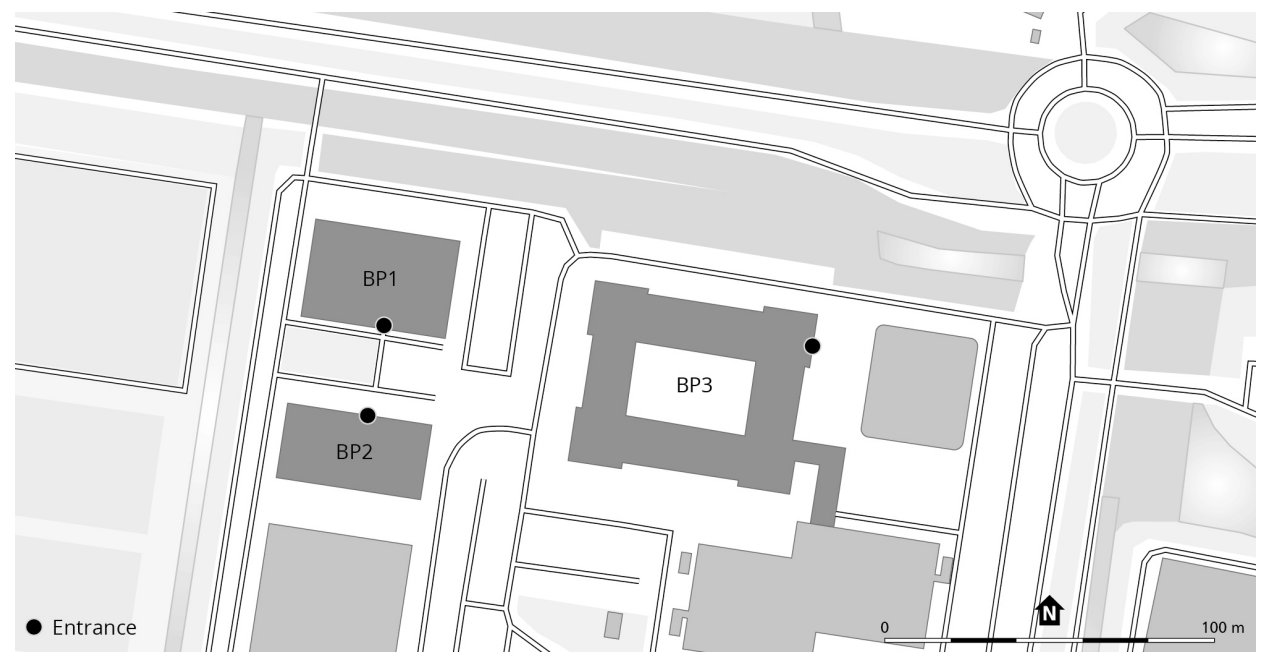

Fig. 1. BioPartner buildings at SciencePark Leiden

Source: own work.

In spite of the favourable conditions for the formation of incubator-internal business networks, some factors seemed to impede the formation of these business networks. For instance, as Fig. 1 shows, the incubator consisted of three different buildings. Additionally, some companies had their own entrances and did not use the main entrances of the buildings. Thus, these entrepreneurs could not be as likely to run into each other compared to a situation where an incubator only has one building and one entrance used by all entrepreneurs. Moreover, the incubator had 
a closed-door policy, which means that entrepreneurs could not enter parts and floors of the building where their firm was not located. Although understandable from the incubator's perspective on safety and privacy, this policy could impeded spontaneous encounters and networking and could affected both the formation of business relationships and the resources exchanged in these relationships.

\section{DATA COLLECTION AND METHODS}

\subsection{Sampling and data collection}

The selection of BioPartner Center Leiden was based on the strong clustering of specialised (biotech) businesses active in the same industry and the specific spatial layout of the three buildings, which enabled us to study spatial proximity at the micro-level. This focus on this single, particular case has limited generalisability but provided us with the opportunity to test the assumptions derived from the literature on the importance of dimensions of proximity for resource exchange.

At the time of the empirical research (2013), not all 47 companies or organizations registered at the incubator were firms or organisations performing research and/or entrepreneurial activity at an office space located in BioPartner Center Leiden. All the organisations that were not engaged in any entrepreneurial activity in the incubator (i.e. they were using it for a mailing address or storage space only or were part of the university) were excluded from the study and were not approached for interview. After we subtracted these eight registered organisations from the list of 47 businesses and organisations, 37 companies and two non-profit organisations could be approached to participate in this study. The two non-profit organisations were regarded as normal cases because they had a physical location and employees in the incubator, and their activities involved other biotechnology companies.

In May 2013, all 39 organisations that were eligible to participate were approached, following a number of steps. A letter was sent first, mentioning the goal of the study and the consent of the incubator manager and inviting the entrepreneurs to participate. Two entrepreneurs responded positively to this letter and were willing to be interviewed. Subsequently, all remaining 37 entrepreneurs were approached by telephone (attempts were made on five different days). In total, 21 entrepreneurs were reached by telephone, 12 of whom were willing to participate. Nine entrepreneurs were not willing to participate. Finally, an e-mail was sent to the remaining 16 entrepreneurs who could not be reached by telephone, and consequently, three interviews were arranged. In total, 17 entrepreneurs were interviewed, nine entrepreneurs were not willing to be interviewed, and the remaining 13 entrepreneurs could not be reached. 
The data was gathered through structured interviews in which a questionnaire was completed. The first part of the questionnaire focused on the firm characteristics of an incubatee and its situation within the incubator, whereas the second part focused on the characteristics of an entrepreneur. Third, questions were asked about the business relationships and specifically which resources were exchanged that were necessary to produce and sell products (but outside the value chain). Fourth, a number of questions were asked about the personal and firm characteristics of the five most important network contacts both within and outside the incubator. The interviews took place at the firm's office, they were recorded with the interviewee's consent, and took 20 to 60 minutes, with an average of 30 minutes. The interviewees mentioned a total of 118 relationships with other businesses: 50 relationships with another incubatee (incubator-internal) and 68 relationships with businesses outside the incubator (incubator-external).

\subsection{Methodology}

In the empirical research design, each unique relationship between a firm and another firm or network contact was regarded as one case. The characteristics of both an interviewee and another network contact were analysed to calculate site proximity, geographical proximity, and personal similarity. To obtain information about the network partners of the interviewees, a highly structured and systematic query technique called the name generator was used to identify network members and to gather information about other network members (the so-called 'alters', Van der Gaag, 2005). All the interviewees were asked to recall five most important incubator-internal and five most important incubator-external network contacts with whom resources were exchanged. To give the interviewees a clue to the kind of contacts that could be provided, a list of examples of resources was mentioned first. Afterwards, the interviewees were asked for more specific information about the other network member and about the specific resource type that was exchanged. The advantage of asking each interviewee to provide information about a number of other parties is that by interviewing a limited number of people, information about many more people can be gathered. Thus, the number of unique relationships becomes much higher than the number of interviewees. An important drawback of this method, however, is that it is a one-sided perspective - only from the viewpoint of an interviewed incubatee. As all information about other network members mentioned by the interviewees was treated confidentially, we could not contact the business partners mentioned by the interviewees to verify the information about the resources exchanged, about other characteristics of the business relationship or about the entrepreneurial characteristics of the business partner. Additionally, since many (incubator-internal) businesses that were mentioned by the participating entrepreneurs did not participate in our study them- 
selves, we could not ask them to assess the business relationship from their side. Regarding business relationships and the resources exchanged, a triangulation of the data gathered was neither possible as in the incubator there were no records available of specific resource exchanges between and the incubatees, and no other sources where this in-depth information was gathered.

We analysed the total set of incubator-internal relationships and incubator-external relationships separately. Each interviewee was asked to mention a maximum of five incubator-internal and five incubator-external business contacts to ensure that data about both types of contacts were gathered. However, because we explicitly asked about an equal number of incubator-internal and incubator-external contacts, both types cannot be pooled, as this would create a biased set. In solving this, both data sets were analysed separately, allowing only a comparison between incubator-internal and incubator-external relationships in terms of the type of exchanged resources.

This study has a cross-sectional design because it has more than one case and was conducted at a single point in time to gather quantitative or quantifiable data (Bryman, 2012). This approach implies that the direction of causal influence detected in the study could be ambiguous. For example, it could be the case that if two parties or two individuals collaborated for a long time, one of them may have moved to the incubator to be more proximate to the other. In short, despite the theoretical evidence for causal relationships between proximity and resource exchange, the design adopted here merely allows for the detection of correlations. Therefore, the term "relationship", rather than "effect", is used when referring to the relationship between dimensions of proximity and resource exchange.

\subsection{Operationalisation}

\subsubsection{Dependent variables}

We asked the interviewees to mention all business partners with whom resources were exchanged and to select five most important partners both within and outside the incubator setting. Supplier and market relationships were intentionally not included. For all resulting 'resource exchanging' business relationships, we asked the interviewees about the types of resources exchanged, and all details were self-reported. Three types of resources were determined: tangible resources, defined as 'anything that can be seen or touched or that has to do with financial matters', and two types of intangible resources: generic business knowledge and business-specific knowledge. During the interviews, a list of examples of resources was shown to the interviewees without mentioning the category to which the examples of resources belonged. Table 2 shows the mentioned examples and indicates to which category they were assigned afterwards. 
Table 2. Examples of each type of resource mentioned by the interviewees and afterwards categorised in the analysis stage

\begin{tabular}{|c|c|c|c|c|c|}
\hline & \multirow{2}{*}{$\begin{array}{l}\text { Tangible } \\
\text { resources }\end{array}$} & \multicolumn{4}{|c|}{ Intangible resources } \\
\hline & & \multicolumn{2}{|c|}{ Generic business knowledge } & \multicolumn{2}{|c|}{ Business-specific knowledge } \\
\hline \multirow{4}{*}{$\frac{\tilde{\theta}}{\bar{Z}}$} & Sharing & Joint venture/ & Market & Ac & Res \\
\hline & Chorin 1 b & Inumer & & & . \\
\hline & $\begin{array}{l}\text { Sharing lab or } \\
\text { office space }\end{array}$ & Investments & $\begin{array}{l}\text { Business ideas/ } \\
\text { concepts }\end{array}$ & $\begin{array}{c}\text { General } \\
\text { scientific ideas/ }\end{array}$ & $\begin{array}{c}\text { Business-related } \\
\text { service }\end{array}$ \\
\hline & $\begin{array}{l}\text { Selling business- } \\
\text { related product }\end{array}$ & $\begin{array}{l}\text { Patents/ } \\
\text { copyrights }\end{array}$ & & & $\begin{array}{c}\text { Specific product } \\
\text { development }\end{array}$ \\
\hline
\end{tabular}

Source: own work.

\subsubsection{Independent variables}

For each relationship, proximity scores were calculated.

- Personal similarity. Personal similarity was determined by comparing the individual characteristics of an interviewed entrepreneur ("entrepreneurial characteristics") to the characteristics of the main contact person of the businesses mentioned by the interviewee. The interviewees themselves chose which person they regarded as the main contact person of the business or organisation they referenced. If it was not immediately clear who the main contact person was, the following question was asked: "Who would you contact first if a major problem occurred in the exchange process?" Four questions were asked about the contact person to gather information about the gender, age, the level of education, and ethnic background of the 118 exchange partners. These details were combined with the data about the gender, age, the level of education, and ethnic background of the interviewees (ego). The total personal similarity score of a relationship was calculated by taking the average score of gender proximity, age proximity, educational proximity and ethnic proximity (see Kruger, 2014 for details on calculations). In the few cases where one or more personal characteristics of the other network member mentioned were missing, for instance, if an interviewee did not know some of the characteristics of the contact person, the personal similarity score was based only on the other characteristics mentioned. Thus, the proximity score of all cases could still be calculated. For all relationships combined, the average similarity score was 0.754 . The total personal similarity score of incubator-internal relationships was 0.820 , whereas the personal similarity score of incubator-external relationships was 0.705 ; however, this difference was not significant (see Table 3).

- Site proximity (for incubator-internal business relationships only). Site proximity is defined as the relative physical distance between two firms within 
the same incubator. Given this definition, site proximity can only be measured between incubatees. Because the incubator consisted of three different buildings, firms located in the same building were closer to each other than firms located in different buildings. Moreover, within the same building, firms that were located on the same floor were closer than firms located on different floors. Site proximity was a categorical variable with three possible outcomes and it was coded as follows into a binary variable: two companies could be located in different buildings (coded 0), in the same building but on different floors (coded 0 ) or in the same building and on the same floor (coded 1). As incubator management provided the actual locations of every incubatee in the three incubator buildings, the site proximity score could be assessed for all incubatees and all the interviewees.

- Geographical proximity (incubator-external business contacts). Geographical proximity resembles the concept of site proximity in that it also applies to the physical distance between two parties. However, whereas site proximity is measured between incubator-internal contacts, geographical proximity is measured between an interviewee and each of their incubator-external contacts. For each external contact, the country of location was inquired, and if the contact was in the Netherlands, the city of location was also inquired, resulting in three categories: outside the Netherlands, within the Netherlands (but outside Leiden), and in Leiden. We used a proxy to measure geographical proximity to the business partner: located in the same city of Leiden (coded 1) or beyond (coded 0 ).

Table 3. Descriptive statistics of the business relationships mentioned by the interviewees

\begin{tabular}{|c|c|c|c|}
\hline Variable & Statistics/answers & Value/share & $(\mathbf{N})$ \\
\hline \multirow{2}{*}{ Personal similarity } & Average: & 0.754 & \multirow{2}{*}{$(118)$} \\
\hline & Standard deviation: & 0.250 & \\
\hline \multirow{2}{*}{$\begin{array}{l}\text { Site proximity (only incubator- } \\
\text { internal relationships) }\end{array}$} & Same floor in building & $70.0 \%$ & \multirow{2}{*}{$(50)$} \\
\hline & Other building or other floor & $30.0 \%$ & \\
\hline \multirow{3}{*}{$\begin{array}{l}\text { Geographical proximity (only } \\
\text { incubator-external relationships) }\end{array}$} & Leiden (same city) & $29.4 \%$ & \multirow{3}{*}{$(68)$} \\
\hline & NL - outside Leiden & $41.2 \%$ & \\
\hline & Abroad & $29.4 \%$ & \\
\hline \multirow{2}{*}{ Age entrepreneur (years) } & Younger than 47 & $45.0 \%$ & \multirow{2}{*}{ (118) } \\
\hline & 47 or older & $55.0 \%$ & \\
\hline \multirow{2}{*}{ Entrepreneurial experience } & No & $50.0 \%$ & \multirow{2}{*}{ (118) } \\
\hline & Yes & $50.0 \%$ & \\
\hline \multirow{2}{*}{ Firm age (years) } & Less than 7 & $24.2 \%$ & \multirow{2}{*}{$(118)$} \\
\hline & 7 or older & $75.8 \%$ & \\
\hline
\end{tabular}




\begin{tabular}{|l|l|c|c|}
\hline \multicolumn{1}{|c|}{ Variable } & \multicolumn{1}{|c|}{ Statistics/answers } & Value/share & \multirow{2}{*}{$(\mathbf{N})$} \\
\hline \multirow{2}{*}{ Time in incubator (years) } & Less than 4 & $54.0 \%$ & \multirow{2}{*}{$(50)$} \\
\cline { 2 - 3 } & 4 or more & $46.0 \%$ & \\
\hline \multirow{2}{*}{ Firm size (number of employees) } & Less than 6 & $48.0 \%$ & \multirow{2}{*}{ (118) } \\
\cline { 2 - 3 } & 6 or more & $52.0 \%$ & \\
\hline
\end{tabular}

Source: own work.

A nonresponse analysis was conducted to analyse whether the group of interviewed entrepreneurs and their firms were representative of the total group of entrepreneurs and firms. This analysis was conducted for the ethnicity, gender, and age of the entrepreneurs and for the building in which they were located, based on two sources of information. The incubator staff provided information about the gender and location of each entrepreneur or firm. Information about the age and ethnic background of the entrepreneurs was not provided by incubator management, so this information had to be deduced from the interviews, in which the incubatees mentioned the characteristics of other incubatees. In total, information about the ethnic background, gender, and age of 30 out of the 39 individual incubatees was gathered. This group of 30 incubatees was used for the nonresponse analysis and compared to the group of 17 interviewed incubatees. The observed values of site proximity were compared to the expected values of site proximity, which were calculated by analysing all potential business relationships of all interviewees. The business relationships between two incubatees were significantly more likely to occur within the same building and on the same floor than between different buildings (results available upon request).

Additional chi-square tests showed that the share of female entrepreneurs, the age distribution and the nationality of the entrepreneurs did not significantly differ between the interviewed entrepreneurs and the total incubatee population. With respect to the exact location of the firms within the incubator, the responding group of entrepreneurs was representative of all incubatees.

\section{THE RESULTS}

Business relationships inside and outside the incubator were substantially different. As Table 4 shows, the types of resources shared differed significantly between business relationships with other incubatees and business relationships with organisations outside the incubator. More business-specific knowledge was exchanged with external partners. 
Table 4. Types of resources per the orientation of business relationship (incubator-internal versus incubator-external)

\begin{tabular}{|l|c|c|c|}
\hline $\begin{array}{l}\text { Types of resources exchanged } \\
\text { in business relationships }\end{array}$ & $\begin{array}{c}\text { Incubator-internal } \\
\text { business relationships }\end{array}$ & $\begin{array}{c}\text { Incubator-external } \\
\text { business relationships }\end{array}$ & Total \\
\hline \multirow{2}{*}{ Tangible resources } & 15 & 25 & 40 \\
\cline { 2 - 4 } & $30.0 \%$ & $36.8 \%$ & $33.9 \%$ \\
\hline \multirow{2}{*}{$\begin{array}{l}\text { Intangible: generic business } \\
\text { knowledge }\end{array}$} & 29 & 7 & 36 \\
\cline { 2 - 4 } $\begin{array}{l}\text { Intangible: business-specific } \\
\text { knowledge }\end{array}$ & $58.0 \%$ & $10.3 \%$ & $30.5 \%$ \\
\hline \multirow{2}{*}{ Total } & 6 & 36 & 42 \\
\cline { 2 - 4 } & $12.0 \%$ & $52.9 \%$ & $35.6 \%$ \\
\cline { 2 - 4 } & 50 & 68 & 118 \\
\hline
\end{tabular}

Chi2 $=35.5 ; \mathrm{p}=0.000$, Cramer's V $=0.548$

Source: own work.

Based on the literature, we hypothesised that personal similarity and site proximity between an incubatee and their business partner would be related to the types of resources shared. However, the literature states that other factors related to an entrepreneur or a business can also be important. We captured this by including the key dimensions of personal similarity, site and geographical proximity, and control factors step by step in the models (Tables 5-7). We expected personal similarity to be positively related to business knowledge exchange instead of the exchange of tangible resources, especially for a specific business knowledge exchange.

Table 5. Parameter estimates of logistic regression analysis on the probability of exchanging intangible resources instead of tangible resources (all 118 business relationships)

\begin{tabular}{|c|c|c|c|c|c|c|c|c|}
\hline \multirow{3}{*}{ Variable } & \multicolumn{8}{|c|}{$\begin{array}{l}\text { Probability of exchanging intangible resources } \\
\text { (instead of tangible resources) }\end{array}$} \\
\hline & \multicolumn{2}{|c|}{ Model 1} & \multicolumn{2}{|c|}{ Model 2} & \multicolumn{2}{|c|}{ Model 3} & \multicolumn{2}{|c|}{ Model 4} \\
\hline & B & S.E. & B & S.E. & B & S.E. & B & S.E. \\
\hline Intercept & -0.479 & 0.607 & 0.557 & 0.931 & 2.109 & 1.557 & 2.655 & 1.825 \\
\hline Personal similarity & 1.545 & $0.781 * *$ & 1.421 & $0.798 *$ & 1.295 & 0.805 & 1.176 & 0.830 \\
\hline \multicolumn{9}{|c|}{ Entrepreneurial characteristics } \\
\hline Age entrepreneur & & & -0.648 & 0.456 & -1.045 & $0.547 *$ & -1.076 & $0.549 * 8 * *+*$ \\
\hline $\begin{array}{l}\text { Entrepreneurial } \\
\text { experience }\end{array}$ & & & 0.158 & 0.453 & 0.318 & 0.482 & 0.339 & 0.482 \\
\hline
\end{tabular}




\begin{tabular}{|c|c|c|c|c|c|c|c|c|}
\hline \multirow{3}{*}{ Variable } & \multicolumn{8}{|c|}{$\begin{array}{l}\text { Probability of exchanging intangible resources } \\
\text { (instead of tangible resources) }\end{array}$} \\
\hline & \multicolumn{2}{|c|}{ Model 1} & \multicolumn{2}{|c|}{ Model 2} & \multicolumn{2}{|c|}{ Model 3} & \multicolumn{2}{|c|}{ Model 4} \\
\hline & B & S.E. & B & S.E. & B & S.E. & B & S.E. \\
\hline \multicolumn{9}{|l|}{ Firm characteristics } \\
\hline Firm age & & & & & -0.724 & 0.473 & 0.339 & 0.482 \\
\hline Firm size & & & & & 0.124 & 0.413 & 0.139 & 0.414 \\
\hline $\begin{array}{l}\text { Incubator-external } \\
\text { relationship }\end{array}$ & & & & & & & -0.247 & 0.426 \\
\hline -2 Log Likelihood & 147.097 & & 144.936 & & 142.576 & & 142.238 & \\
\hline Cox \& Snell R Square & 0.034 & & 0.051 & & 0.070 & & 0.073 & \\
\hline Nagelkerke R Square & 0.046 & & 0.071 & & 0.097 & & 0.100 & \\
\hline
\end{tabular}

$* * * p<.01 ; * * p<.05 ; * p<.1$ (two-tailed tests).

Source: own work.

The models in the above Table 5, depicting the probability that in the business relations mentioned, either generic or business-specific knowledge (intangible resources) are exchanged instead of tangible resources, show that at first sight (Model 1), personal similarity between business partners was positively and significantly related to the exchange of business knowledge. This effect, however, decreased in both significance and size when we verified the entrepreneurial and firm characteristics of the ego. In particular, the age of the entrepreneur seemed to be important: older entrepreneurs tended to exchange fewer intangible (i.e. more tangible) resources than younger ones. Perhaps they have surpassed the stage of information exchange, eventually resulting in the exchange of concrete, tangible resources. Models 3 and 4 show that including firm characteristics - and especially the difference between incubator-internal and incubator-external relationships - did not affect the size or the positive/negative inclination of the model parameters significantly, although the effect of personal similarity was no longer significant. However, considering the small change and the persistence of the positive/negative inclination and size of the parameter, we suspect that this was due to the small number of cases. It seems that personal similarity between business partners was slightly positively related to the exchange of intangible resources. Taking a closer look at the role of personal similarity in both generic and specific business knowledge exchange renders the results depicted in Table 6.

Table 6 focuses on the two types of intangible resource exchange. Regarding the exchange of generic business knowledge, personal similarity seemed to be of no importance, and all parameters of the control variables were also insignificant. 


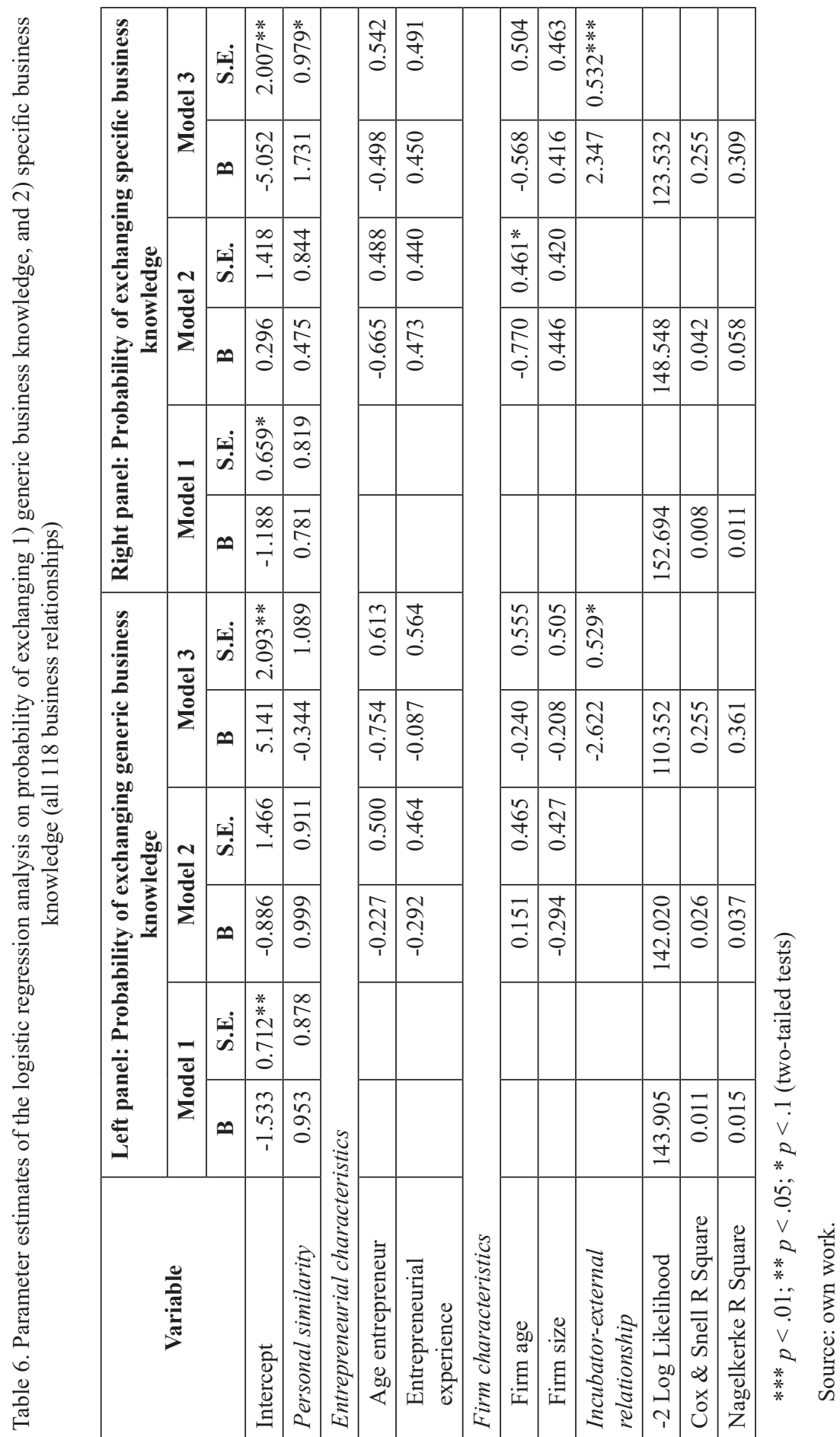




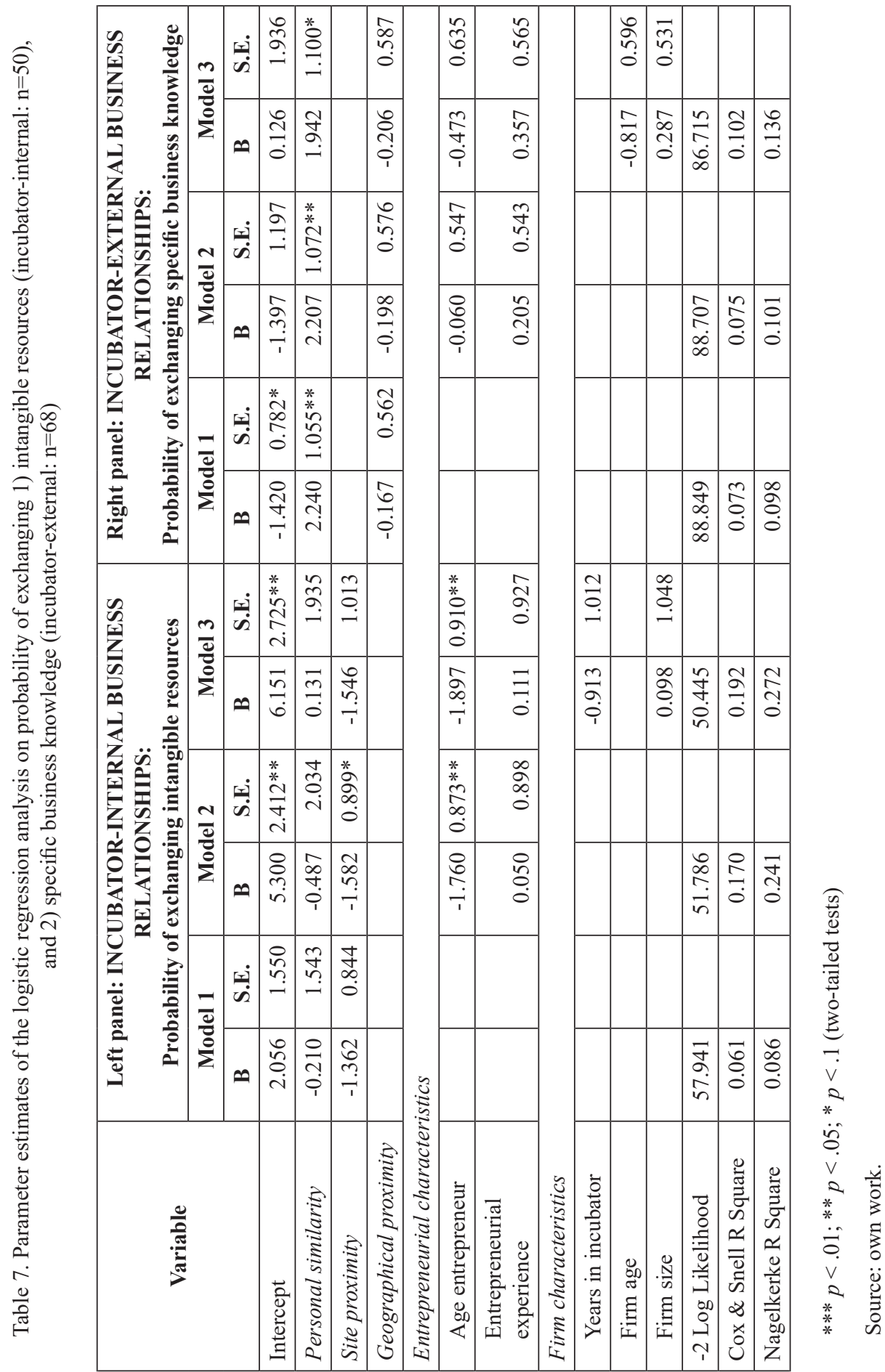


Model 3 in the left panel of Table 6, however, shows that in incubator-external relationships, far less generic business knowledge was exchanged than in incubator-internal business relationships. This closely mirrored the results of the analysis of the effect of incubator-external partnerships on the exchange of specific human capital: model 3 in the right panel depicts a significant and large positive effect of incubator-external relationships. In this latter analysis, however, personal similarity was also positively related to the exchange of specific business knowledge, hinting that the fact of personally resembling a business partner increased the chance of sharing specific and detailed information and knowledge when the location of this business partner was controlled.

Differentiating between incubatees' relationships with businesses within and outside the incubator enabled us to see whether the other two dimensions of spatial proximity (site and geographical proximity) mattered for the types of resources exchanged. The two panels in Table 7 present the results of the analyses on exchanging intangible resources and exchanging specific human capital resources for incubator-internal and incubator-external business relationships, respectively. Due to the small number of business relationships, further detail was not possible. However, the fact of distinguishing between incubator-internal and incubator-external relationships enables us to focus on the effects of site proximity and geographical proximity, respectively, in addition to the personal similarity dimension. For incubator-internal business relationships, we used 'years in incubator' instead of 'firm age', as these characteristics were highly correlated. Our argument here was that the time spent in the incubator was far more relevant for incubator-internal business relationships than for incubator-external business relationships.

In relationships between businesses whose sites were very proximate - that is, businesses located on the same floor of the incubator - tangible resources were exchanged more often than in relationships between businesses located on another floor or in another building. This effect decreased in significance; however, the positive/negative inclination and the size did not change much when control variables were included (left panel: models 2 and 3), suggesting that this result was caused by the small number of cases but rather by interfering effects of control variables. In particular, we found that older entrepreneurs exchanged fewer intangible resources within the incubator than their younger counterparts did. This could indicate that young entrepreneurs were still sharing information and knowledge, as they had not reached the stage of concrete resource sharing.

For the 68 relationships with businesses outside the incubator, geographical proximity did not affect the probability of exchanging specific human capital (Table 7, right panel). In other words, whether the other network member was located abroad or in the Netherlands, inside or outside Leiden, it was of no importance to the exchange of specific knowledge and information. However, as we already expected from Table 6, personal similarity had a positive effect on the exchange 
of specific human capital resources - and this effect endured when we checked for other factors. For incubator-external relationships, the physical proximity of incubatees or the ease of visiting nearby businesses seemed to be compensated by sharing business partner characteristics.

We conclude that hypothesis 1 , i.e. that personal similarity positively impacts the exchange of business-specific knowledge, was partly accepted; meaning it could not be rejected entirely. The positive inclination for all 118 relationships involved was no longer significant after we checked for other factors; however, when only the incubator-external relationships were included, personal similarity substantially enhanced business-specific knowledge exchange in relationships. Hypothesis 2 must be rejected because the positive relation between being located on the same floor and exchanging tangible relationships lost significance when other factors were taken into account. However, this might be due to the small number of cases, as the parameter positive/negative inclination was robust and relatively large and positive.

\section{CONCLUSION AND DISCUSSION}

The overall aim of this study was to investigate whether personal similarity and geographical proximity are related to the types of resources exchanged in the business relationship of incubatees, both within and outside an incubator setting.

It should not be ignored that to the incubatees interviewed, incubator-external network partners seemed to be more important for resource exchange than incubator-internal contacts. In this respect, the term BioPartner is perhaps slightly euphemistic. However, our results also suggest that site proximity plays a (albeit small) role in the resources exchanged between incubatees: it seems that tangible resources are more often exchanged if firms are located on the same floor. The mechanism here can be that neighbouring incubatees regularly and frequently run into each other and, therefore, see, witness, and discuss practical matters or basic problems instead of discussing business-specific issues in depth. Our finding is in line with the evidence from the ethnographic research of Cooper et al. (2012) of a positive effect of site proximity on the likelihood of collaboration between two firms in the same incubator. Geographical proximity was found to be unrelated to the types of resources exchanged with incubator-external business partners. With respect to personal similarity, the results suggested that this dimension of proximity, combining the personal characteristics of an entrepreneur and network members, might influence the resources exchanged through business relationships. This new concept, constructed from the pivotal work of Boschma, Vissa and Caniëls et al., calls for new tests with more cases in different contexts and 
incubator settings. Regarding the latter, Redondo-Carretero and Camarero-Izquierdo (2017) recommended looking at incubatees' eagerness to interact, their sense of belonging to the incubator area, and affective commitment. Our findings are only partly consistent with the literature. The types of resources exchanged in business relationships, however, were hard to predict in our models. The finding that entrepreneur age is positively related to the exchange of tangible resources in incubator-internal relationships was rather unexpected and calls for further research. It may be true that older entrepreneurs are less hesitant to share material goods than to exchange intangible (knowledge) resources, perhaps as a result of past experiences or risk-avoiding behaviour. This might be related to recent academic findings on inter-firm relations suggesting that a firm's purpose of collaboration (Usman et al., 2019) and a combination of trust and control (Massaro et al., 2019) matter for knowledge transfer.

It is important to note that this study had methodological limitations that may have affected its reliability and validity. First, due to the cross-sectional character of this study, the relationships between some factors analysed could be correlational rather than causal, or the causality may be different than assumed. Second, the number of missing cases was rather high. Instead of including all potential relationships between firms and their network contacts within the incubator, the study examined only 50 inter-incubator relationships mentioned by the interviewees. Third, due to confidentiality, we could not verify the types of resources exchanged or the entrepreneurial characteristics of business partner contacts mentioned by the incubatees interviewed. Furthermore, at the relationship level of the analysis, all relationships were treated as independent cases, whereas in fact, each firm could have had multiple relationships with one or more business partners. Therefore, a multilevel analysis would have been an appropriate method of analysing the results, grouping the relationships based on the firm to which they belonged. Last, this study was conducted in only one specific incubator setting. The relationships between proximity and business relationship characteristics may depend on the characteristics of the incubator, the sector of the incubator, the surrounding environment of the incubator (such as a larger science park), and cultural factors. Therefore, the findings of this study may not be applicable to firms in incubators in other sectors or countries. However, the study results, especially the name-generating technique to identify business partners, can be of use in reproducing the study in other incubator settings, business sites or even clusters.

Despite its methodological caveats, this study provides at least three new insights into how an incubator can shift from being a collection of similar yet independent firms to a geographical cluster where incubatees collaborate and externalities emerge. Although site proximity only seemed to matter for the exchange of tangible resources, such relationships might evolve over time into the exchange of specific human capital resources. However, a transition from exchanging lab equipment to collaborating on a research project was likely only if the two parties 
involved could benefit from the partnerships. This was usually the case only if two firms were active in the same niche of biotechnology. A first recommendation to incubator managers is, therefore, to locate firms that are active in the same sector in each other's (geographical) vicinity - and by this we mean the same floor rather than just the same building. In the case of an incubator with different buildings, it would even be possible to make thematic buildings, each with firms active in a specific niche of biotechnology. A second suggestion is to rethink the incubator's closed-door policy, as this might limit the opportunities for collaboration between incubatees. If entrepreneurs are not able to enter the buildings, the floors, or the parts of the floors where they are not located themselves, the chances of coincidentally meeting other incubatees decline. The closed-door policy is understandable from the perspective of the incubator, but it would be good to reconsider its advantages (privacy) and its disadvantages. Finally, as some entrepreneurs attend events and conferences to meet other incubatees, the fact of frequently organising networking events or network drinks in the incubator or elsewhere at the science park can also contribute to the formation of the incubator-internal network.

One may conclude that the limited importance of the incubator to the resources exchanged in the incubatees' business network means that geographical proximity does not play a role and that a geographical cluster with resulting externalities cannot be found at BioPartner Center Leiden. However, this would be an erroneous conclusion. It may be that the incubator setting itself is not essential for the resources exchanged in the business network of the incubatees, but the firms, organisations and citizens in the vicinity of the incubator are. In line with Capdevila (2015), we argue that instead of being seen as independent and isolated organisations, coworking spaces and university incubators should be seen as pieces of a larger specialised cluster, within which externalities do emerge as a result of contact between geographically proximate parties. Our quantitative attempt to test whether proximity dimensions matter for resources exchanged by incubatees gives some answers but also raises new questions on how to capture, measure, and subsequently stimulate (spatial) the spill-over effects of micro-level proximity. Therefore, we encourage future research that uses different data collection methods on the resource exchange by and business relationships between incubatees, for instance, using in-depth interviews of both parties, documents, narratives or observations.

\section{REFERENCES}

AGRAWAL, A., KAPUR, D. and MCHALE, J. (2008), 'How do spatial and social proximity influence knowledge flows? Evidence from patent data', Journal of Urban Economics, 64 (2), pp. 258-269. https://doi.org/10.1016/j.jue.2008.01.003 
AHMAD, A. (2014), 'A mechanisms-driven theory of business incubation', International Journal of Entrepreneurial Behaviour \& Research, 20, pp. 375-405. https://doi.org/10.1108/ IJEBR-11-2012-0133

BEHRENS, J., PATZELT, H., SCHWEIZER, L. and BÜRGER, R. (2012), 'Specific managerial human capital, firm age, and venture capital financing of biopharmaceutical ventures: A contingency approach', The Journal of High Technology Management Research, 23 (2), pp. 112-121. https://doi.org/10.1016/j.hitech.2012.06.003

BEUGELSDIJK, S. and MUDAMBI, R. (2013), 'MNEs as border-crossing multi-location enterprises: The role of discontinuities in geographic space', Journal of International Business Studies, 44 (5), pp. 412-426. https://doi.org/10.1057/jibs.2013.23

BIOPARTNER CENTER LEIDEN (n.d.), Retrieved 26 February 2013, from http://www.biopartnerleiden.nl.

BLISSON, D. and RANA, B.K. (2001), 'The role of entrepreneurial networks: the influence of gender and ethnicity in British SMEs', Paper presented at the 46th ICSB World Conference, Taipei, Taiwan, June. Available at http://citeseerx.ist.psu.edu/viewdoc/download?do$\mathrm{i}=10.1 .1 .199 .833 \& \mathrm{rep}=\mathrm{rep} 1 \&$ type $=\mathrm{pdf}$

BOSCHMA, R. (2005), 'Proximity and Innovation: A Critical Assessment', Regional Studies, 39 (1), pp. 61-74. https://doi.org/10.1080/0034340052000320887

BRYMAN, A. (2012), Social research methods, New York: Oxford University Press.

BUYS, A.J. and MBEWANA, P.N. (2007), 'Key success factors for business incubation in South Africa: the Godisa case study', South African Journal of Science, 103 (9-10), pp. 356-358.

BYGRAVE, W. (1988), 'The structure of the investment networks of venture capital firms', Journal of Business Venturing, 3 (2), pp. 137-157. https://doi.org/10.1016/0883-9026(88)90023-7

CANIËLS, M.C.J., KRONENBERG, K. and WERKER, C.W. (2014), 'Conceptualizing Proximity in Research Collaborations', [in:] RUTTEN, R.P.J.H., BENNEWORTH, P., IRAWATI, D. and BOEKEMA, F. (eds.), The Social Dynamics on Innovation Networks, From Learning Region to Learning in Socio-Spatial Context, London and New York: Routledge.

CAPDEVILA, I. (2015), 'Co-working spaces and the localized dynamics of innovation in Barcelona', International Journal of Innovation Management, 19 (03), pp. 1-25. https://doi.org/10.1142/ S1363919615400046

COOPER, E., HAMEL, S. and CONNAUGHTON, S. (2012), 'Motivations and Obstacles to Networking in a University Business Incubator', The Journal of Technology Transfer, 37 (4), pp. 433-453. https://doi.org/10.1007/s10961-010-9189-0

CZARNITZKI, D. and HOTTENROTT, H. (2011), 'R\&D investment and financing constraints of small and medium-sized firms', Small Business Economics, 36 (1), pp. 65-83. https://doi. org/10.1007/s11187-009-9189-3

D'ESTE, P., GUY, F. and IAMMARINO, S. (2012), 'Shaping the formation of university-industry research collaborations: what type of proximity does really matter?' Journal of Economic Geography, 13 (4), pp. 537-558. https://doi.org/10.1093/jeg/lbs010

EISENHARDT, K.M. and SCHOONHOVEN, C.B. (1996), 'Resource-based view of strategic alliance formation: Strategic and social effects in entrepreneurial firms', Organization Science, 7 (2), pp. 136-150. https://doi.org/10.1287/orsc.7.2.136

EVELEENS, C.P., VAN RIJNSOEVER, F.J. and NIESTEN, E.M.M.I. (2017), 'How network-based incubation helps start-up performance: a systematic review against the background of management theories', Journal of Technological Transfer, 42, pp. 676-713. https://doi.org/10.1007/ s10961-016-9510-7

FREEMAN, J., CARROLL, G.R. and HANNAN, M. (1983), 'The Liability of Newness: Age Dependence in Organizational Death Rates', American Sociological Review, 48 (5), pp. 692-710. https://doi.org/10.2307/2094928 
FUZI, A. (2015), 'Co-working spaces for promoting entrepreneurship in sparse regions: the case of South Wales', Regional Studies, Regional Science, 2 (1), pp. 462-469. https://doi.org/10.1080/ 21681376.2015.1072053

GRANOVETTER, M. (1985), 'Economic action and social structure: The problem of embeddedness', American journal of sociology, 91 (3), pp. 481-510. https://doi.org/10.1086/228311

HACKETT, S. and DILTS, D. (2004), 'A Systematic Review of Business Incubation Research', Journal of Technology Transfer, 29, pp. 55-82. https://doi.org/10.1023/B:JOTT.0000011181.11952.0f

HARRISON, B. (2007), 'Industrial Districts: Old Wine in New Bottles?' (Volume 26, Number 5, 1992), Regional Studies, 41, pp. S107-S121. https://doi.org/10.1080/00343400701232264

JAFFE, A.B., TRAJTENBERG, M. and HENDERSON, R. (1993), 'Geographic localization of knowledge spillovers as evidenced by patent citations', The Quarterly Journal of Economics, 108 (3), pp. 577-598. https://doi.org/10.2307/2118401

KATZ, B., VEY, J.S. and WAGNER, J. (2015), One year after: Observations on the rise of innovation district, Brookings, 24 June 2015, https://www.brookings.edu/research/one-year-after-observations-on-the-rise-of-innovation-districts/.

KRUGER, M. (2013), Ego-Alter Networks in University Business Incubators: The Case of BioPartner Center Leiden, Master Thesis Economic Geography, Utrecht University.

MASON, J.K., OSHRI, I. and LEEK, S. (2012), 'Shared learning in supply networks: evidence from an emerging market supply network', European Journal of Marketing, 46 (11), pp. 1743-1762. https://doi.org/10.1108/03090561211260077

MASSARO, M., MORO, A., ASCHAUER, E. and FINK, M. (2019), 'Trust, control and knowledge transfer in small business networks', Review in Managerial Science, 13, pp. 267-301. https:// doi.org/10.1007/s11846-017-0247-y

MCADAM, M. and MCADAM, R. (2006), 'The networked incubator: The role and operation of entrepreneurial networking with the university science park incubator (USI)', The International Journal of Entrepreneurship and Innovation, 7 (2), pp. 87-97. https://doi. org/10.5367/000000006776928663

MCADAM, M. and MARLOW, S. (2008), 'A Preliminary Investigation into Networking Activities within the University Incubator', International Journal of Entrepreneurial Behaviour \& Research, 14 (4), pp. 219-241. https://doi.org/10.1108/13552550810887390

MCADAM, M., GALBRAITH, B., MCADAM, R. and HUMPHREYS, P. (2006), 'Business Processes and Networks in University Incubators: A Review and Research Agendas', Technology Analysis \& Strategic Management, 18 (5), pp. 451-472. https://doi.org/10.1080/09537320601019578

MCCANN, B. and FOLTA, T. (2011), 'Performance differentials within geographic clusters', Journal of Business Venturing, 26 (1), pp. 104-123. https://doi.org/10.1016/j.jbusvent.2009.04.004

MCPHERSON, M., SMITH-LOVIN, L. and COOK, J.M. (2001), 'Birds of a Feather: Homophily in Social Networks', Annual Review of Sociology, 27, pp. 415-444. https://doi.org/10.1146/ annurev.soc.27.1.415

MICEK, G. (2019), 'Geographical Proximity Paradox Revisited: The Case of IT Service SMEs in Poland', Sustainability, 11 (20), p. 5570. https://doi.org/10.3390/su11205770

MOZUMDAR, L., HAGELAAR, G., MATERIA, V.C., OMTA, W.W.F., ISLAM, M.A. and VAN DER VELDE, G. (2019), 'Embeddedness or over-embeddedness? Women Entrepreneurs' Networks and Their Influence on Business Performance', The European Journal of Development Research, 31, pp. 1449-1469. https://doi.org/10.1057/s41287-019-00217-3

PARRINO, L. (2015), 'Coworking: Assessing the Role of Proximity in Knowledge Exchange', Knowledge Management Research \& Practice, 13 (3), pp. 261-271. https://doi.org/10.1057/kmrp.2013.47

PETERS, L., RICE, M. and SUNDARARAJAN, M. (2004), 'The role of Incubators in the Entrepreneurial Process', Journal of Technology Transfer, 29, pp. 83-91. https://doi.org/10.1023/B:J OTT.0000011182.82350.df 
POLANYI, M. (1958), Personal knowledge: Towards a post-critical philosophy, Chicago, Illinois: University of Chicago Press.

REDONDO-CARRETO, M. and CAMARERO-IZQUIERDO, C. (2017), 'Relationships between Entrepreneurs in Business Incubators. An exploratory case study', Journal of Business-to-Business Marketing, 24 (1), pp. 57-74. https://doi.org/10.1080/1051712X.2016.1275826

SMITH, J. and POWELL (2004), 'Knowledge Networks as Channels and Conduits: The Effects of Spillovers in the Boston Biotechnology Community', Organization Science, 15 (1), pp. 5-21. https://doi.org/10.1287/orsc. 1030.0054

SNEL, D. and BRUINS, A. (2004), Oudere versus jongere starters, EIM, Onderzoek voor Bedrijf \& Beleid. Available at http://ondernemerschap.panteia.nl/pdf-ez/a200410.pdf

SOETANTO, D. and JACK, S. (2011), 'Business incubators and the networks of technology-based firms', The Journal of Technology Transfer, 38 (4), pp 432-453. https://doi.org/10.1007/s10961011-9237-4

SØRHEIM, R. (2003), 'The pre-investment behaviour of business angels: a social capital approach', Venture Capital, 5 (4), pp. 337-364. https://doi.org/10.1080/1369106032000152443

TORRE, A. and RALLET, A. (2005), 'Proximity and localization', Regional studies, 39 (1), pp. 47 59. https://doi.org/10.1080/0034340052000320842

USMAN, M., AHMAD, M.I. and BURGOYNE, J. (2019), 'Individual and organizational learning from inter-firm knowledge sharing: a framework integrating inter-firm and intra-firm knowledge sharing and learning', Canadian Journal of Administrative Sciences, 26, pp. 484-497.

VAN DER GAAG, M.P.J. (2005), Measurement of individual social capital, Groningen, University of Groningen.

VAN RIJNSOEVER, F.J., VAN WEELE, M.A. and EVELEENS, C.P. (2017), 'Network brokers or hit makers? Analyzing the influence of incubation on start-ups investments', International Entrepreneurship and Management Journal, 13 (2), pp. 605-629. https://doi.org/10.1007/ s11365-016-0416-5

VERBRUGGE, L.M. (1977), ‘The structure of adult friendship choice', Social Forces, 56, pp. $577-$ 597. https://doi.org/10.2307/2577741

VERHEUL, I. and THURIK, R. (2001), 'Start-up capital: «does gender matter?»', Small Business Economics, 16 (4), pp. 329-346. https://doi.org/10.1023/A:1011178629240

VISSA, B. (2010), 'A Matching Theory of Entrepreneurs' Tie Formation Intentions and Initiation of Economic Exchange', INSEAD Working Paper No. 2010/06/EFE. Available at https://ssrn.com/ abstract=1550086. https://doi.org/10.2139/ssrn.1550086

WILLIAMSON, O.E. (1958), The economic institutions of capitalism, New York, New York: Free Press.

ZENG, Y., LIU, J. and GEORGE, G. (2010), 'The dynamic impact of innovative capability and inter-firm network on firm valuation: A longitudinal study of biotechnology start-ups', Journal of Business Venturing, 25 (6), pp. 593-609. https://doi.org/10.1016/j.jbusvent.2009.02.001

ZHANG, J. (2011), 'The advantage of experienced start-up founders in venture capital acquisition: evidence from serial entrepreneurs', Small Business Economics, 36 (2), pp. 187-208. https://doi. org/10.1007/s11187-009-9216-4 